Published in final edited form as:

Otolaryngol Head Neck Surg. 2015 November ; 153(5): 795-798. doi:10.1177/0194599815601659.

\title{
Early T Stage Salivary Duct Carcinoma: Outcomes and Implications for Patient Counseling
}

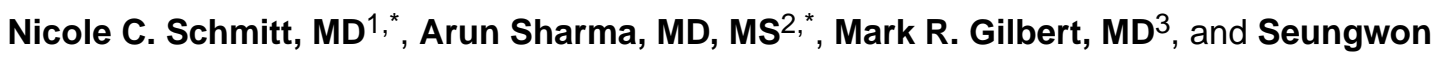 \\ Kim, MD ${ }^{3}$ \\ ${ }^{1}$ Department of Otolaryngology-Head and Neck Surgery, Johns Hopkins University, Baltimore, \\ Maryland, USA \\ ${ }^{2}$ Division of Otolaryngology-Head and Neck Surgery, Southern Illinois University, Springfield, \\ Illinois, USA \\ ${ }^{3}$ Department of Otolaryngology-Head and Neck Surgery, University of Pittsburgh, Pittsburgh, \\ Pennsylvania, USA
}

\begin{abstract}
Salivary duct carcinoma (SDC) is a rare salivary malignancy that often presents at advanced stage. Outcomes of low T stage patients with SDC have not been previously examined in detail. We queried our institution's cancer database and identified 28 patients with SDC in situ or T1/T2 SDC. A retrospective chart review was performed, followed by comparison of clinicopathologic features with $\mathrm{N}$ stage, disease-free survival, and overall survival. Patients tended to be male, in their sixties, with a high incidence of regional metastases, as in prior reports. Five-year diseasefree and overall survival were $49 \%$. Median disease-free survival was 3.24 years, and overall survival was 4.65 years. Parotid location, vascular invasion, facial nerve sacrifice, and extracapsular extension were associated with worse survival. This study provides practical information for counseling of patients who undergo surgery for a parotid mass and are found to have this aggressive malignancy.
\end{abstract}

\section{Keywords}

salivary malignancy; salivary duct carcinoma

\footnotetext{
Reprints and permission: sagepub.com/journalsPermissions.nav

Corresponding Author: Seungwon Kim, MD, Department of Otolaryngology-Head and Neck Surgery, University of Pittsburgh, 200 Lothrop Street, Suite 519, Pittsburgh, PA 15213, USA. kimsw2@upmc.edu.

These authors contributed equally to this article.

No sponsorships or competing interests have been disclosed for this article.

Author Contributions

Nicole C. Schmitt, data collection and analysis, writing and revision of the manuscript; Arun Sharma, data collection and analysis, review and revision of the manuscript; Mark R. Gilbert, data collection and analysis, review and revision of the manuscript;

Seungwon Kim, study supervision, review and revision of the manuscript.

Disclosures

Competing interests: None.

Sponsorships: None.

Funding source: None.
} 
Salivary duct carcinoma (SDC) is a distinct salivary malignancy that histologically resembles ductal carcinoma of the breast. ${ }^{1}$ SDC is more aggressive than the more common salivary malignancies, with 5-year overall survival (OS) ranging from $42 \%$ (stage I) to $23 \%$ (stage IV). ${ }^{2,3}$ There is a predominance of men in their fifth or sixth decade. ${ }^{2-4}$ SDC usually involves the parotid gland and can arise de novo or as a carcinoma ex pleomorphic adenoma. ${ }^{2-5}$ The mainstay of therapy is surgery, followed by adjuvant radiation. Little evidence is available regarding the efficacy of chemotherapy. ${ }^{2,4,5}$ Agents targeting androgen receptors and human epidermal growth factor receptor 2 (HER-2/neu) have been used with favorable responses. ${ }^{3-9}$ However, the prognosis remains poor, with a high incidence of locoregional recurrence and distant metastases. $2,4,5,7,8$

We recently treated several patients presenting with a parotid mass thought to be a pleomorphic adenoma who were found to have SDC. Indeed, a painless mass in the parotid gland may be the most common presenting symptom. ${ }^{4}$ This prompted us to review our institution's outcomes with early T stage SDC, to better understand the prognosis for patients found to have SDC by surprise. Twenty-eight patients with early-stage SDC were identified, and clinicopathologic features were compared with survival.

\section{Methods}

\section{Patient Selection}

A search of our institution's head and neck oncologic database was conducted for all pathologic diagnoses of "salivary duct carcinoma" made by our head and neck pathologists ${ }^{10}$ between January 1995 and October 2014. Clinical information and staging (based on computed tomography scans and pathology) were obtained from the database and medical records. This study was approved by the University of Pittsburgh Institutional Review Board.

\section{Statistical Analysis}

Categorical variables (eg, sex) were compared with chi-square and, when appropriate, Fisher's exact tests. Age was compared between groups with the Mann-Whitney test. Survival was compared between groups by describing the median disease-free survival (DFS) and OS. The log rank test was used to compare survival statistically, while Cox proportional hazards models were generated to estimate hazards ratios. All $P$ values were calculated with 2-sided hypotheses. The threshold for statistical significance was set at $P<$. 05; however, given the small sample size and associated possibility of type II error, we also reported $P<.10$ as nearly significant. Statistical analyses were conducted with STATA 11.1 Intercooled (StataCorp, College Station, Texas).

\section{Results}

Of 75 total SDC patients, 28 low T stage patients were identified: $7 \%$ with in situ disease, $43 \%$ with $\mathrm{T} 1$ disease, and $50 \%$ with $\mathrm{T} 2$ disease. Twenty $(71 \%)$ were male, and median age was 64 years. Twenty-one (75\%) masses were in the parotid gland; $5(18 \%)$ were in the submandibular gland; 1 was in the hard palate; and 1 had an unknown primary site. The majority presented with a painless parotid mass. Computed tomography imaging most often 
showed a well-circumscribed parotid mass, and $62 \%$ of the documented fine-needle aspiration biopsies suggested malignancy. Sixteen patients (57\%) had a smoking history. Over half the tumors were classified as carcinoma ex pleomorphic adenoma. HER-2/neu expression was positive in $21 \%$, negative in $11 \%$, and unknown in the remaining cases. All patients underwent surgical resection, and 64\% underwent neck dissection; of those who had a neck dissection, 1 was pathologically staged as N0, $4(22 \%)$ as N1, and $13(72 \%)$ as N2. Among the 4 patients who were clinically N0 and who underwent neck dissection, 1 was found to have N1 disease, and 2 were found to have N2b disease. Negative margins were obtained in 79\% of cases. Eleven patients (39\%) underwent adjuvant radiation; 9 (32\%) underwent chemoradiation; and 8 (29\%) had no adjuvant therapy. Perineural, vascular, and extracapsular invasion were associated with $\mathrm{N}$ stage (Table 1). Parotid location, vascular invasion, facial nerve sacrifice, and extracapsular invasion were associated with worse survival (Table 2). Adjuvant therapy had no effect on survival but was offered primarily to patients with nodal disease. The 5-year DFS and OS were $49.2 \%$ and $49.3 \%$, respectively (Figure 1). Median DFS and OS were 3.24 and 4.65 years. Recurrent disease, when noted, first occurred at the primary site and/or the neck in all cases.

\section{Discussion}

Data presented in this study provide practical information for counseling of patients who are unexpectedly found to have SDC. While it has been suggested that smaller primary tumors may be associated with better survival, prior series included small numbers of patients and showed mixed results. ${ }^{11,12}$ One SEER Medicare database study of 228 patients showed survival differences based on tumor size but did not classify the tumors by $\mathrm{T}$ stage. ${ }^{11} \mathrm{We}$ found that DFS is only about 3 years even with early T stage disease. Limitations of our study include its retrospective nature, small number of patients, and heterogeneous use of adjuvant therapy.

All patients in our series underwent surgical resection, and most had adjuvant radiation. Radiation may improve locoregional control, but it is unclear whether it improves survival. ${ }^{11}$ There is a high incidence of occult nodal metastasis; therefore, neck dissection should be considered even for the clinically N0 neck. ${ }^{2,3}$ Further studies of chemotherapy or targeted regimens are needed. In patients who undergo resection of pleomorphic adenoma, development of SDC has been reported up to 28 years later. ${ }^{2}$ Accordingly, patients with benign parotid neoplasms should be counseled that recurrence of a parotid mass warrants follow-up.

\section{Conclusion}

Early T stage SDC can be surgically resected with negative margins in the majority of cases. However, SDC is an aggressive malignancy, and prognosis remains poor even for patients with low $\mathrm{T}$ stage disease. 


\section{References}

1. Kleinsasser O, Klein HJ, Hubner G. Salivary duct carcinoma. A group of salivary gland tumors analogous to mammary duct carcinoma. Arch Klin Exp Ohren Nasen Kehlkopfheilkd. 1968; 192:100-105. [PubMed: 4301301]

2. Jaehne M, Roeser K, Jaekel T, Schepers JD, Albert N, Loning T. Clinical and immunohistologic typing of salivary duct carcinoma: a report of 50 cases. Cancer. 2005; 103:2526-2533. [PubMed: 15900577]

3. Wee DT, Thomas AA, Bradley PJ. Salivary duct carcinoma: what is already known, and can we improve survival? J Laryngol Otol. 2012; 126(suppl 2):S2-S7. [PubMed: 22495125]

4. Salovaara E, Hakala O, Back L, et al. Management and outcome of salivary duct carcinoma in major salivary glands. Eur Arch Otorhinolaryngol. 2013; 270:281-285. [PubMed: 22437251]

5. Jaspers HC, Verbist BM, Schoffelen R, et al. Androgen receptor-positive salivary duct carcinoma: a disease entity with promising new treatment options. J Clin Oncol. 2011; 29:e473-e476. [PubMed: 21422415]

6. Perissinotti AJ, Lee Pierce M, Pace MB, El-Naggar A, Kies MS, Kupferman M. The role of trastuzumab in the management of salivary ductal carcinomas. Anticancer Res. 2013; 33:25872591. [PubMed: 23749912]

7. Nashed M, Casasola RJ. Biological therapy of salivary duct carcinoma. J Laryngol Otol. 2009; 123:250-252. [PubMed: 18405406]

8. Nabili V, Tan JW, Bhuta S, Sercarz JA, Head CS. Salivary duct carcinoma: a clinical and histologic review with implications for trastuzumab therapy. Head Neck. 2007; 29:907-912. [PubMed: 17563907]

9. Williams MD, Roberts D, Blumenschein GR Jr, et al. Differential expression of hormonal and growth factor receptors in salivary duct carcinomas: biologic significance and potential role in therapeutic stratification of patients. Am J Surg Pathol. 2007; 31:1645-1652. [PubMed: 18059220]

10. Williams L, Thompson LD, Seethala RR, et al. Salivary duct carcinoma: the predominance of apocrine morphology, prevalence of histologic variants, and androgen receptor expression. Am J Surg Pathol. 2015; 39:705-713. [PubMed: 25871467]

11. Jayaprakash V, Merzianu M, Warren GW, et al. Survival rates and prognostic factors for infiltrating salivary duct carcinoma: analysis of 228 cases from the Surveillance, Epidemiology, and End Results database. Head Neck. 2014; 36:694-701. [PubMed: 23606370]

12. Guzzo M, Di Palma S, Grandi C, Molinari R. Salivary duct carcinoma: clinical characteristics and treatment strategies. Head Neck. 1997; 19:126-133. [PubMed: 9059870] 
A

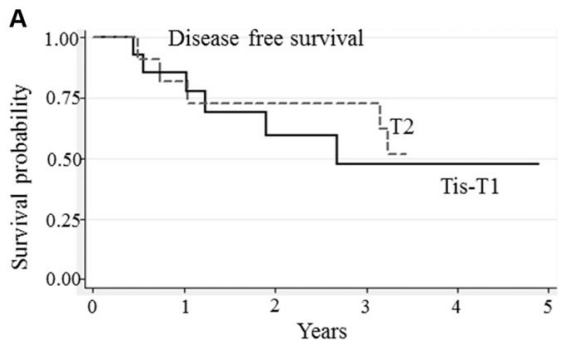

B

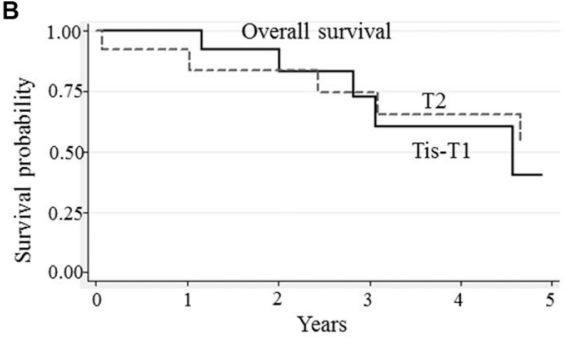

Figure 1.

Kaplan-Meier curves showing disease-free and overall survival according to T stage. 


\section{Table 1}

Patient and Tumor Characteristics of Early T Stage Salivary Duct Carcinoma by Nodal Status. ${ }^{a}$

\begin{tabular}{|c|c|c|c|}
\hline & \multicolumn{2}{|c|}{ Stage, $\mathrm{n}(\%)^{b}$} & \multirow{2}{*}{$P$ Value } \\
\hline & N0-1 $(n=11)$ & $\mathrm{N} 2(\mathrm{n}=14)$ & \\
\hline Age, y, median & 65 & 63 & .784 \\
\hline Sex: female & $4(36)$ & $4(29)$ & 1.000 \\
\hline Smoking history & & & 1.000 \\
\hline Nonsmoker & $5(45)$ & $5(36)$ & \\
\hline Smoker & $6(55)$ & $8(57)$ & \\
\hline Unknown & 0 & $1(7)$ & \\
\hline Alcohol history & & & .820 \\
\hline Nondrinker & $4(36)$ & $3(21)$ & \\
\hline Drinker & $6(55)$ & $10(71)$ & \\
\hline Unknown & $1(9)$ & $1(7)$ & \\
\hline Tumor subsite & & & .480 \\
\hline Parotid gland & $9(82)$ & $11(79)$ & \\
\hline Submandibular gland & $2(18)$ & $1(7)$ & \\
\hline Other/unknown & 0 & $2(14)$ & \\
\hline Carcinoma ex pleomorphic adenoma & $6(55)$ & $6(43)$ & .561 \\
\hline \multicolumn{4}{|l|}{ Invasion } \\
\hline Perineural & $4(35)$ & $12(86)$ & .030 \\
\hline Extracapsular & $1(9)$ & $9(64)$ & .011 \\
\hline Vascular & $2(18)$ & $11(79)$ & .004 \\
\hline HER-2/neu & $3(27)$ & $2(14)$ & .836 \\
\hline Facial nerve sacrifice & $3(27)$ & $5(36)$ & 1.000 \\
\hline
\end{tabular}

Abbreviation: HER-2/neu, human epidermal growth factor receptor 2.

${ }^{a}$ Characteristics that were significantly or nearly significantly associated with $\mathrm{N}$ stage are shown in bold.

${ }^{b}$ All values are presented in $\mathrm{n}(\%)$, except for age. 


\section{Table 2}

Univariate Analysis of Disease-Free and Overall Survival in Patients with Early T Stage Salivary Duct Carcinoma. $^{a}$

\begin{tabular}{|c|c|c|c|c|}
\hline & \multicolumn{2}{|c|}{ Disease-Free Survival } & \multicolumn{2}{|c|}{ Overall Survival } \\
\hline & HR $(95 \%$ CI $)$ & $P$ Value & HR $(95 \%$ CI $)$ & $P$ Value \\
\hline Age, $y, \geq 65$ & $1.10(0.33-3.63)$ & .876 & $0.84(0.26-2.70)$ & .767 \\
\hline Sex: female & $0.40(0.09-1.88)$ & .232 & $0.32(0.07-1.50)$ & .129 \\
\hline Smoking history: smoker & $1.11(0.32-3.82)$ & .872 & $0.75(0.21-2.69)$ & .659 \\
\hline Alcohol history: drinker & $0.67(0.19-2.34)$ & .532 & $1.16(0.31-4.39)$ & .829 \\
\hline Tumor subsite: submandibular gland & $\mathbf{0}^{b}$ & .014 & $0.14(0.02-1.13)$ & .035 \\
\hline \multicolumn{5}{|l|}{ Stage } \\
\hline $\mathrm{T} 2$ & $0.80(0.24-2.66)$ & .713 & $0.72(0.23-2.30)$ & .580 \\
\hline $\mathrm{N} 2$ & $0.81(0.25-2.65)$ & .725 & $1.07(0.32-3.55)$ & .908 \\
\hline Carcinoma ex pleomorphic adenoma & $0.54(0.17-1.79)$ & .308 & $0.55(0.17-1.75)$ & .302 \\
\hline \multicolumn{5}{|l|}{ Invasion } \\
\hline Perineural & $3.08(0.66-14.31)$ & .130 & $2.01(0.43-9.47)$ & .370 \\
\hline Extracapsular & $2.74(0.78-9.68)$ & .103 & $7.04(1.38-36.05)$ & .007 \\
\hline Vascular & $5.79(0.70-48.27)$ & .069 & $3.49(0.68-17.94)$ & .116 \\
\hline HER-2/neu positive & $0.25(0.02-2.73)$ & .216 & $0.18(0.02-2.05)$ & .124 \\
\hline Facial nerve sacrifice & $6.32(1.55-25.71)$ & .003 & $7.06(1.42-35.24)$ & .006 \\
\hline \multicolumn{5}{|l|}{ Adjuvant therapy } \\
\hline Radiation & $1.03(0.20-5.37)$ & .970 & $0.46(0.11-1.99)$ & .299 \\
\hline Chemoradiation & $1.66(0.30-9.07)$ & .561 & $0.60(0.12-2.96)$ & .533 \\
\hline
\end{tabular}

Abbreviation: CI, confidence interval; HER-2/neu, human epidermal growth factor receptor 2; HR, hazard ratio.

${ }^{a}$ Characteristics that were significantly or nearly significantly associated with disease-free or overall survival are shown in bold.

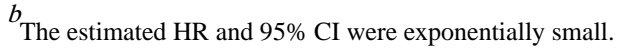

